\title{
The Virtual Reconstruction of Historical and Cultural Heritage Monuments of the Vodyansky Settlement
}

\author{
I.A. Romanova ${ }^{1}$, N.M. Poluboyarova ${ }^{2}$ \\ Volgograd State University \\ 1 ORCID: 0ooo-0oo2-5718-7414, irina.romanova@volsu.ru \\ 2 ORCID: oooo-0002-3973-7574, natasha medvedeva@volsu.ru
}

\begin{abstract}
The preservation and restoration of historical memorials play very important roles in the formation of a holistic view of material culture and technology level in different society development periods. But material reconstruction of some memorials cannot be realized due to different reasons. In such cases, modern $3 \mathrm{D}$ technologies provide a wide range of modeling tools.

In this paper we give an example of virtual reconstruction of the cathedral mosque of the Vodyanskoe gorodishche (Vodyansky settlement) using terrain map for building a landscape. We also use the materials of archaeological excavations to create plausible textures for minaret and portal decoration. The modeling is based on reliable data from archaeological reports and on probabilistic data based on the architectural traditions of the region in the same period.

The virtual reconstruction was implemented via Blender, an open-source $3 \mathrm{D}$ computer graphics software

This work was supported by the Ministry of Education and Science of Russia (the project "Development of Virtual 3D Reconstruction of Historical Objects Technique", scientific theme code 2019-0920, project number in the research management system FZUU-0633-20200004).
\end{abstract}

Keywords: 3D visualization, reconstruction of historical objects, virtual reconstruction, osm maps, landscape detailing, Vodyansky settlement, Blender.

\section{Introduction}

When we talk about the Volgograd region and its landmarks, we should understand that the memorial complex "Mamayev Kurgan" is the most famous for people. The museum "Old Sarepta" is the second well-known place. But the history of the region is much richer. However, few non-specialists are familiar with it and its landmarks. One of these unique sites is the Vodyansk settlement. Many historians assume that this is the Golden Horde city of Beldjamen (for example, [1, 2]). This is one of the archeological monuments of federal significance in the Volgograd region. Adopted for state protection by the Decree of the Council of Ministers of the RSFSR No. 624 dated December 4, 1974. The Vodyansky settlement is located near the town of Dubovka, Volgograd Region, and is one of the most interesting monuments of the Golden Horde in the Lower Volga region.

The history of the study of the Vodyansky settlement dates back to the 8os. XIX century. You can learn more about it in [3]. Since 1989, the Volga-Akhtuba archaeological expedition has been working annually at the Vodyansky settlement.

Particular interest in this settlement is due to the fact that, on the one hand, materials of two cultural traditions of the XIV century - Russian and Central Asian, are well represented 
here, and on the other hand, the almost century-old history of this city reflects various stages of development of the Golden Horde state from its inception to decline [4].

Despite the fact that many periods of the history of the Vodyansky settlement are already quite clear, every year, during the excavations it is possible to find new interesting objects, burial and economic complexes, which allow not only to clarify, but to open new pages in the history of the city, material culture and occupations of its inhabitants [5]. Nevertheless, there is practically no chance of physical preservation of this historical monument due to the annual coastal landslides (the change in the coastline is shown in Figure 1 [6]). Thanks to archaeological expeditions, it is possible to obtain information about at least a part of the entire volume of medieval residential and economic structures, to preserve what is possible. Therefore, we would like to draw attention to the historical and cultural heritage of the region with the help of a virtual reconstruction of the architectural objects of the Vodyansky settlement. Perhaps, thanks to our project, there will be opportunities for financial support for the study, preservation, and rescue excavations at the Vodyansky settlement from the funds of state and non-state scientific funds.

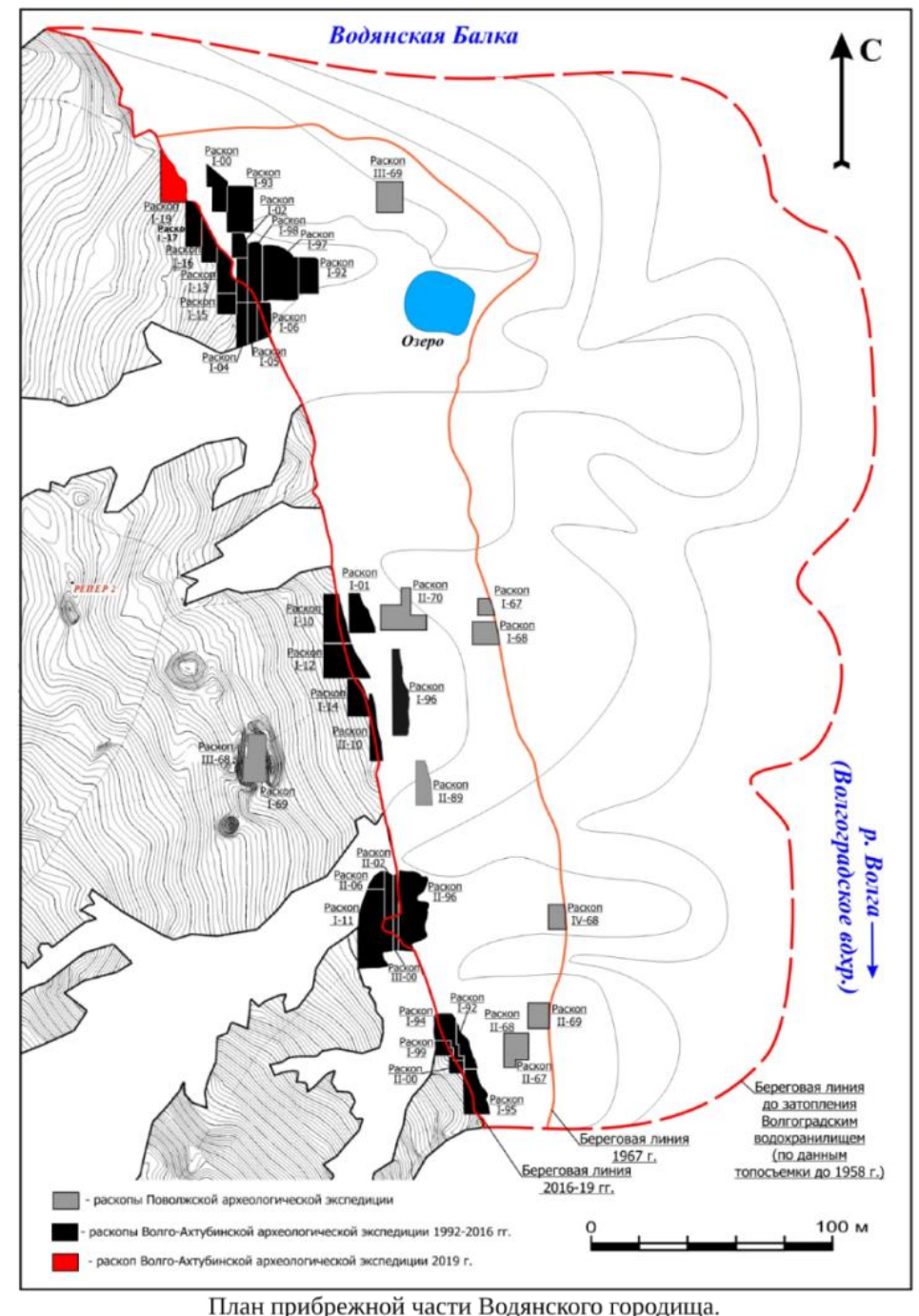

Figure 1. Plan of the coastal part of the Vodyansky settlement

This article presents some of the results of the project "Development of the methodology for virtual 3D reconstruction of historical objects", carried out in the laboratory of spatial data analysis, reconstruction and modeling. Educational activity was chosen as one of the goals of the ongoing research. Another task relates to the technical aspects of the project. This is the development of an application for archaeologists, which does not require special IT 
knowledge from the user. Nevertheless it should allow to build high-quality visualization based on a certain set of typical models and materials, and it should take into account some general architectural principles. For example, during excavations the foundation of a residential building was found. A specialist can determine the size of the dwelling, the material of the walls and other details from the find. Wet assume that our application will help to create a three-dimensional model of a house based on a set of shapes, materials and textures characteristic of the area, the historical period, the culture under study. This would help novice researchers to roughly imagine the object of study, and perhaps help with further excavations. This would facilitate the teaching process for the mentors of students group.

Here is the virtual reconstruction's result of the cathedral mosque of the Vodyansky settlement. This researching serves the starting point for finding work methods for detailing the landscape, modeling various courtyard buildings with the changeable materials for their shading.

\section{Relevance}

Virtual reconstruction projects based on three-dimensional technologies can perform various tasks [7]. These are the following

- virtual reconstruction of lost cultural monuments based on historical documents;

- modeling of existing cultural monuments with the possibility of their virtual visit;

- creation of a cartographic area with corresponding historical settlements;

- virtual reconstruction of historical events using three-dimensional characters (military operations, migrations, religious rituals, etc.);

- reconstruction of lost interior items and digitization of antiques to create thematic multimedia applications, as well as to create a single electronic library.

Thus, the use of virtual reconstruction allows to obtain new scientific data based on reliable historical information and presented using modern information technologies.

Digital modeling of archaeological and architectural monuments in their current state and reconstruction of their intended appearance in the past are recognized not only as a way of visualizing the genesis of a historical place to the public, but also as an effective research tool. Search for historical sources, their proper analysis, and interdisciplinary relationship between technological disciplines and humanities are fundamental for obtaining reliable hypothetical reconstructions [8].

By visualizing archaeological sites and excavations (existing, reconstructed or proposed), users can not only get to know them, but also view the elements of the objects presented from different points of view. In general, reconstruction allows you to interpret, analyze and understand the complexity of the object [9]. So, using the example of the Vodyansky settlement mosque, we faced with many questions that were not present before the virtual reconstruction started. What materials were used for windows and roofs? What was the interior of the dwellings? All these questions arise when you make a proper work plan.

Virtual reconstructions display things in three-dimensional space and therefore users can imagine that they are moved to another century. A lot of details, such as decorative elements of the interior, the number of steps, the scale and neatness of dwellings, plants, animals, household items, etc. help to complement the illusion. The authenticity of these little things is of particular importance in virtual reconstructions. A special approach is required for objects or buildings that have not been preserved in their original form at all, or have been preserved in part. In cases when there is no exact information about the forms of the missing parts of the object, the exterior elements are restored on the basis of historical documents and descriptions, or on the basis of accepted art and architectural traditions and techniques. We think it would be interesting to provide the possibility of special marking of existing (or reliably described) parts, probable and conditional for such models. So, for greater clarity, boats and carts, doors and roofs were used in the layout of the mosque. It is clear that wooden structures have not survived to this day. But there is a lot of evidence of developed fishing in the settlement, so it was logical to place the conventional image of the boat in a virtual reconstruction for greater realism. In addition, if there are several reasonable hypotheses 
regarding the appearance of the object, the $3 \mathrm{D}$ model allows to make several variations of the scene.

This flexibility relies on an important advantage of virtual reconstructions: they are cheaper than physical reconstructions. They can also be completed in a much shorter time frame. Accessibility and mobility are other important features of virtual models: they can be available for view in one or more places, such as in a museum, university or research center, or they can be published on the Internet. In addition, the models can be adapted for $3 \mathrm{D}$ printing. Obviously, virtual spaces containing reconstructed monuments can be used not only for tourism, scientific and educational and other public presentations, but they are excellent materials for scientific research and training of specialists in this field.

There are many examples of the use of computer technologies related to threedimensional modeling of monuments. There are both domestic (russian) [10] and foreign [11] collections of works which represent interesting approaches to virtualization and analysis of the programs used for the convenience of their use for historical reconstructions. One of the possible options for the visual presentation of the results of large-scale historical and theoretical studies of the architectural heritage of the region is given in [12].

The most ambitious reconstruction projects in the open access today are the international project-gallery of virtual reconstructions of the historical and cultural heritage "Vizerra" (http://vizerra.com) and the joint Russian-German project "Reconstruction of the Moscow Kremlin" (http: // www.kreml.ru) [13].

A high level of reliability is a significant feature of such projects. This means that all important objects in the virtual space look exactly the same as do in reality (in case of nonexistent objects, as they did). In the case of modeling of ruined objects it often happens that the actual information is not enough for visualization. Then, to ensure the accuracy of reconstructing, it is necessary to work in close cooperation with historians, archaeologists, museum staff and other specialists in the subject area. The scenes obtained this way can be used as a basis for scientific research due to the high level of authenticity.

Speaking about the study of the current work, we can argue that there is no precedent of a $3 \mathrm{D}$ computer reconstruction of the archaeological sites of the Vodyansky settlement. Therefore, the project was started with the cathedral mosque which is the largest and most studied building of the settlement. Already existing successful experience of creating a mosque mockup by I.Y. Lapshina and A.A. Skorobogatov played an important role in the choice of this object. The model of the mosque is being displayed in the Volgograd Regional Museum of Local Lore (see fig. 2).

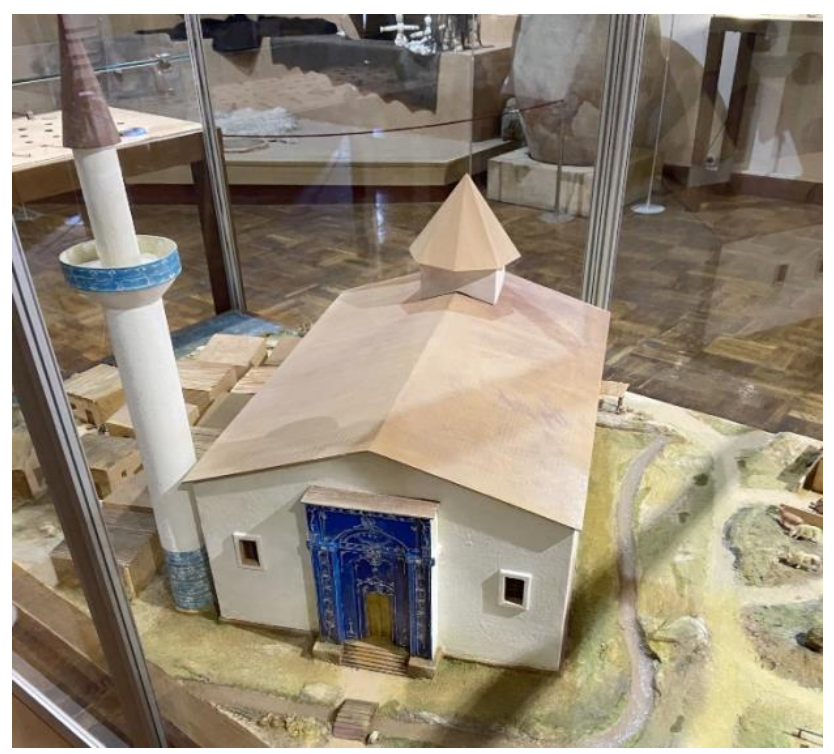

Figure 2. The mockup of the cathedral mosque in the regional museum of local lore (Photo provided by Kiyashko Ya. A.) 
Figure 3 shows a view of the Vodyansky settlement in June 2020. This area is protected and it is a tourist landmark. But, as you can see from the photo this section of the steppe doesn't look like a historical monument at all. All archaeological objects lie at a depth of about $0.5 \mathrm{~m}$ or lower. A virtual reconstruction and preservation of the historical heritage is actually needed. The $3 \mathrm{D}$ model of the mosque could be placed on display in a museum, in information booklets for tourists, for example, as shown in Figure 4. At the same time, the model is presented on a virtual map in its historical location and with landscape preserved in general terms. This helps to vividly imagine the view that no longer exists.

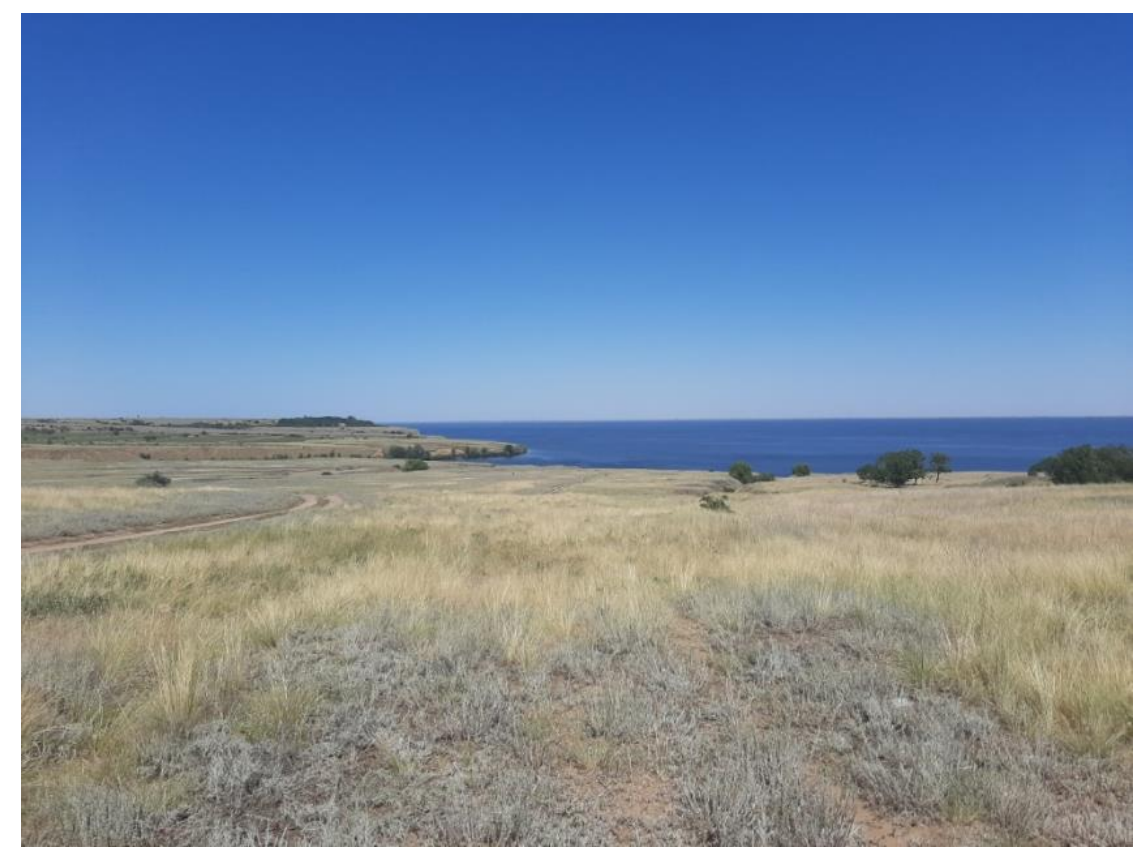

Figure 3. View of the Vodyansky settlement, 2020

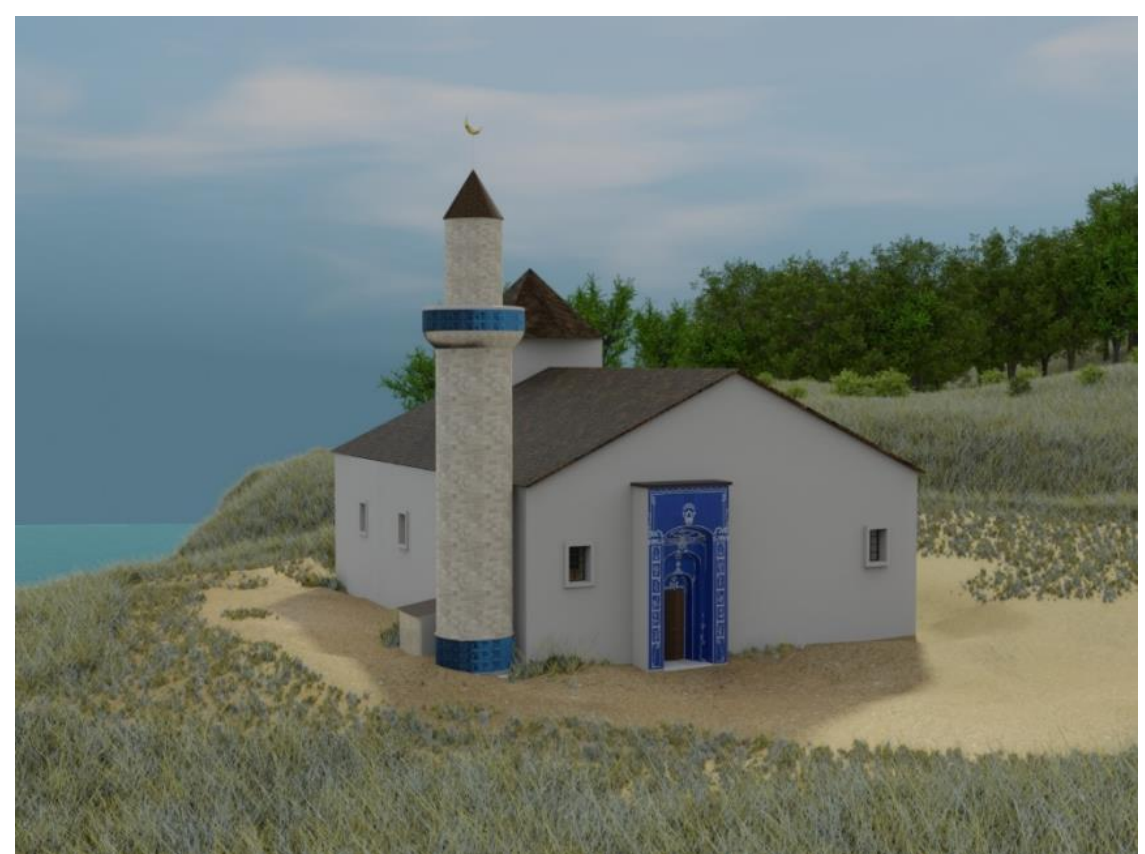

Figure 4. Virtual reconstruction of the mosque of the Vodyansky settlement

\section{Description of the object}

The central object of the virtual reconstruction of the Vodyansky settlement is the cathedral mosque, discovered during excavations in 1971-1973. Presumably, the mosque was built in the second half of the XIV century and was destroyed during Timur's campaigns against the Golden Horde about 1391-1395. Thus, the object was only partially preserved, and 
its reconstruction has a probabilistic nature. The first step of modeling was to collect reliable data. The main sources are the article-report on the excavations of V.L.Yegorov and FedorovDavydov G.A. [14], as well as materials from the article by L.M. Noskova [15], and exhibits of the Volgograd Museum of Local Lore.

According to archaeological data, the following reliable features of the modeling object can be distinguished. We will cite mainly those that relate to the appearance of the mosque or serve as the basis for conclusions about the external features.

1. Location and dimensions. The mosque was a rectangular basilica with a base of 26 by 35 meters, stretched from north to south, oriented by the mihrab to the southeast. There is a building plan in [14].

2. Wall materials. The main part of the walls was built of fine torn stone on clay mortar. The inside of the mosque was covered with white plaster, outside the north and east walls were plastered (at least traces of plaster and clay on other walls are not recorded in the sources). In the eastern wall, closer to the northeastern corner, part of the masonry is replaced by brick.

3. Internal organization. In the south wall there was a mihrab, made of halves of bricks and faced with white plaster. The plan clearly shows a rectangular area in front of the mihrab, which was separated from the rest of the space by a balustrade with columns resting on stone bases.

4. Portal. The entrance located on the north side. It was decorated with two pylons (100 $\mathrm{cm}$ wide from west to east), the space between them was $300 \mathrm{~cm}$. The total width of the portal was $500 \mathrm{~cm}$. The width of the doorway was $132 \mathrm{~cm}$. In the doorway there was a threshold made of three hewn stones. The entrance location was not central. This is clearly followed from the plan.

5 . Minaret. In the north-eastern corner of the building, a rectangular masonry $(500 \times 420$ $\mathrm{cm}$ ) of the minaret base was found. It was made from large stone slabs. Above the plinth, obviously, there was a round trunk of the minaret, made of burnt bricks,which had an arcshaped rib. . Since bricks of two radii of curvature were found during the excavations, it is likely that the lower part was wider than the upper one. The surface of the minaret was decorated with tiles with turquoise glaze. The tiles were alternated with ganch inserts with inscriptions and patterns imprinted on them. Stamps are divided into four types (see Fig. 5, bottom row from left to right):

a. a character similar to an Arabic letter,

b. the names Allah and Muhammad, written in Kufi handwriting,

c. incomprehensible inscription in Arabic,

d. dot squared.

Only the foundation and walls to a height within a meter from the mainland were preserved by the time of the excavations. Thus, the reconstruction of the complete exterior of the mosque has probabilistic nature and is based on the general principles of the monumental cult architecture of the Golden Horde of the XIV century. 


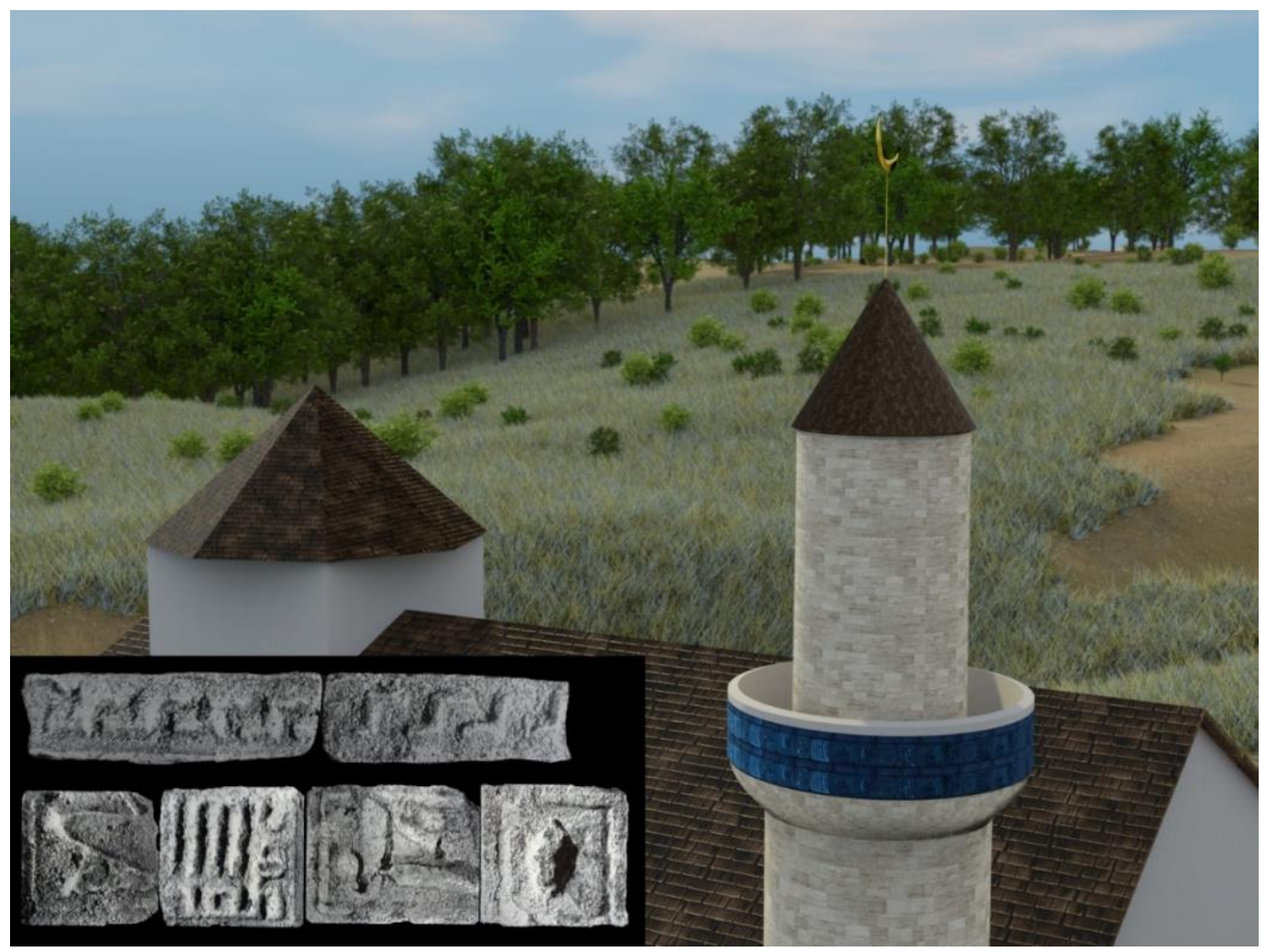

Figure 5. Imprints on ganch tiles and the type of texture obtained on their basis for the decor of the balcony of the minaret

As noted by Zelevinskaya E.D. [16, 17], the canons of the Asia Minor mosques of the Seljuk period had influenced the architectural traditions of the Golden Horde. This led to the widespread occurrence of basilica-type premises, which can be easily traced in most of the foundations found. It should also be assumed that other elements were borrowed, such as a flat or gable roof, the possible presence of a small dome above the pre-shrine part, and the structure of a portal. This hypothesis is fully confirmed, for example, by the mosque of Khan Uzbek in the Old Crimea (Solkhat).

\section{Modeling the mosque}

The basis for the construction of a model of a mosque at the Vodyansky settlement was the excavation plan of 1971-1973 [14]. As noted in this work, and which is clearly visible on the plan, certain miscalculations were made during the laying the foundation. They mainly concerned the position and length of the western wall. However, these features were not taken into account in modeling, since construction errors were corrected and did not affect the appearance of the mosque. Another note regarding reliable data relates to the portal. The report [14] describes two stages of the portal functioning. On the first, it had two pylons and, apparently, looked like it was typical for Seljuk mosques of that period: it had an aivan construction and was richly decorated. Fragments of decor were found and represent stone tiles with blue glaze, with white underglaze plant patterns and inscriptions, elements of overglaze painting [15]. Fragments of the facing are kept in the Volgograd Museum of Local Lore [18].

At the second stage of the portal's functioning, the eastern pylon was destroyed (or dismantled), while the western one remained standing. Since the authors of this article did not find any mentions of other portals with one pylon, the symmetrical version of the first stage was chosen for modeling.

Other assumptions relate to the part of the mosque that has not preserved. They appeal to the traditional forms of monumental architecture of that period, and they are described above in the previous section. 
In the process of creating a virtual reconstruction of the mosque, the contour of the walls was built according to the excavation plan. As reference points for the heights of the main building of the mosque and the minaret, the mosque of Khan Uzbek in the old Crimea and the minarets of the Bolgar (for example, [19-21]) are used. The walls of the mosque are equipped with window openings. The location of the openings was chosen conventionally in such a way that the window would fall into the gap between the columns and ensure the unhindered penetration of light inside. Since there is no mention of the use of clay tiles or any durable roof covering material at the excavation site, it is generally assumed that a wood equivalent was used.

For texturing the main part of the complex, scanned three-dimensional PBR materials from open sources were used. The decorative facing of the minaret was created on the basis of photographs of four types of ganch stamps and dividing patterns (see Fig. 5). Since the minaret was completely destroyed, it is not established reliably in what order these patterns followed each other and whether they formed one wide belt or several.

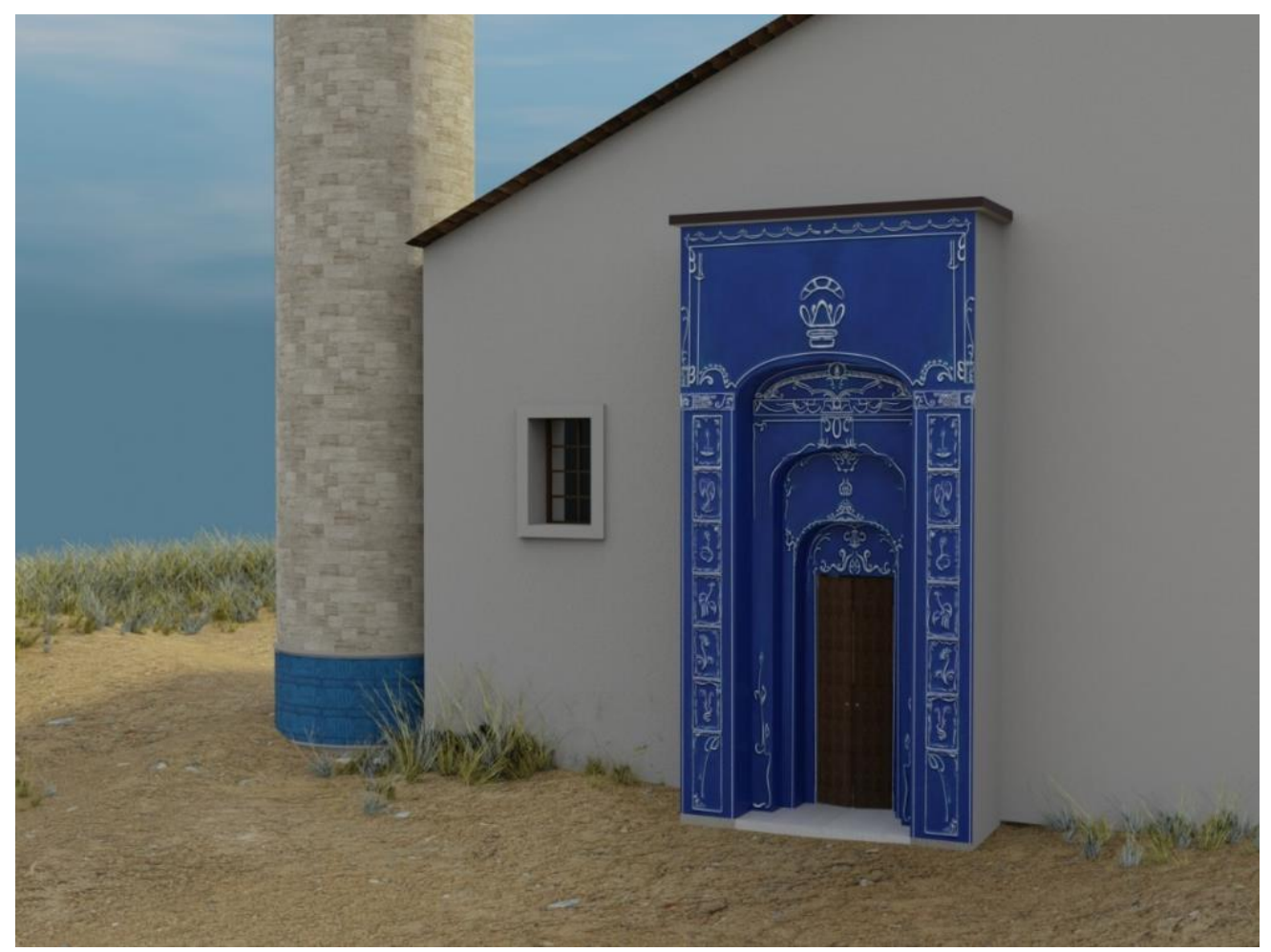

Figure 6. Location of ganch inserts on the lower tier of the minaret, view of the portal

Thus, the work done on the virtual reconstruction of the mosque and its surrounding buildings has given a certain groundwork, which can be used in the future for the development of the application. We assume that it will function as an add-on to the Blender $3 \mathrm{D}$ graphics package. This will allow the archaeologist to place objects from a set of standard buildings models on the existing plan already in the course of excavations. The main part of poor urban quarter buildings were quite of the same type, so its models can be added to the scene while specifying only the parameters of sizes and textures without additional researching. Manors, a mosque and a bathhouse are unique structures, so it will be possible to add a contour for them. Proper modeling of buildings of this level as a rule needs more study, and it should be done in the $3 \mathrm{D}$ laboratory. So, a $3 \mathrm{D}$ model of the landscape will be created with ready-made "standard" buildings and contours of "unique" buildings placed on it will become an additional result of archaeological expedition's work. This will greatly simplify the work on the general $3 \mathrm{D}$ reconstruction of the Vodyansky settlement. The application can also be used to model settlements of the Golden Horde that are close in time of existence and location to the one under consideration. 


\section{Terrain modeling}

To establish a universal approach to modeling any square of the terrain that would be suitable for archaeologists in field conditions we used "fast earth modeling". To do this, we used the free addon blender-smd for Blender. It allows to quickly transfer the terrain from the OSM map to a plane in the Blender editor (the "OpenStreetMap" project is a joint creation and free distribution of detailed maps of the whole world [22]). This plane will act as the ground of the selected terrain square, which needs to be made more detailed using standard Blender tools. To import a territory, you need to know the coordinates of the imported area. To make the modeling process more accurate, you need a satellite photo from a map, for example, a screenshot from Google Earth.

This is not the only approach to terrain modeling. For example, authors of [23] use landscape design programs (L3DT, Terragen) to create a 3D landscape model based on the available topographic data (maps, plans, schemes, images from space).

Here is a description of recreating the landscape in the Blender editor. Import the image in the same pop-up menu in the osm tab, select the import type as 'image overlay' and click on the import button. The image will start loading, than it will automatically be placed on the landscape as a material. We get the following result (see Fig. 7).

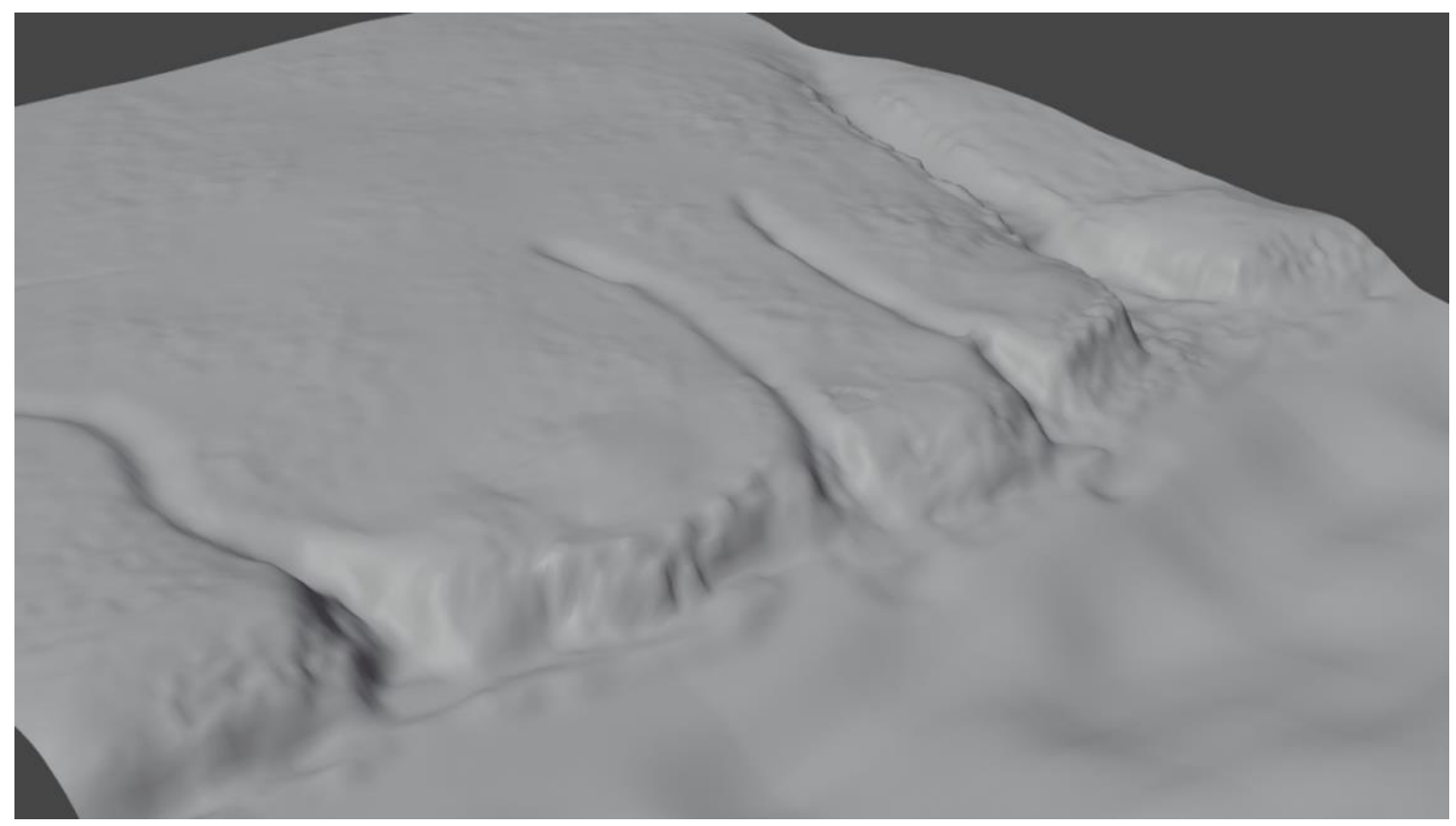

Figure 6. Terrain model

Further, two strategies can be used. The first one is useful when it is necessary to quickly show probable situations during excavations. Then it is possible to place prepared objects (a house, a well, part of a wall, etc.) on the already obtained relief. The second strategy should be applied for proper modeling of the final version of the virtual reconstruction. This means more clearly designing the steep terrain, adding water, applying textures and environmental elements (grass, soil, etc). At this stage, the process is not yet automated, work continues in this direction. As a result of automation, the archaeologist will have to master the marking mechanism (Fig. 8), add textures that are prepared in advance for this area and only need to select the necessary ones from the list (approximately the same result is shown in Figure 8), and add environmental elements (also from the list of prepared ones, result in Figure 10). We plan to carry out the automation according to the same principle as the "fast fur" function was implemented in the Blender program. 


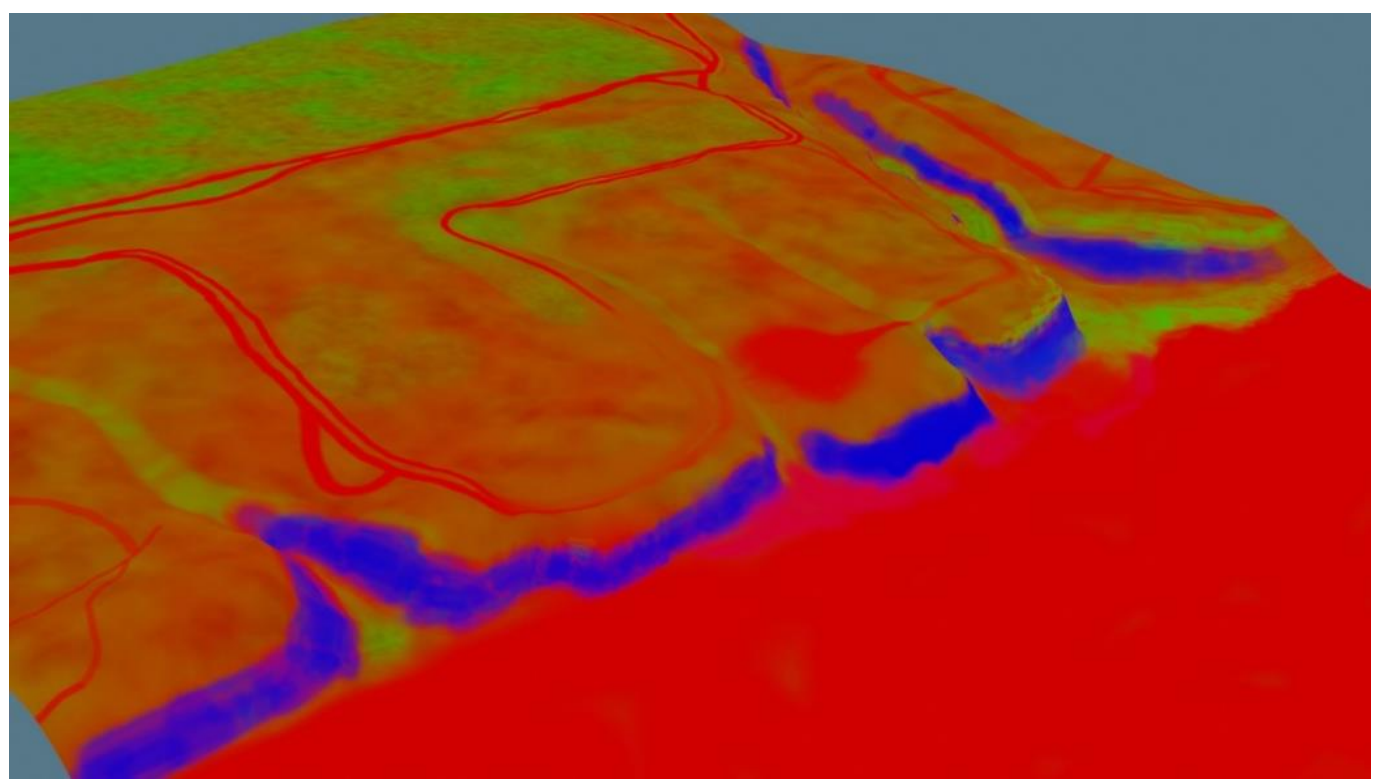

Figure 7. Selecting vertex groups using a mask

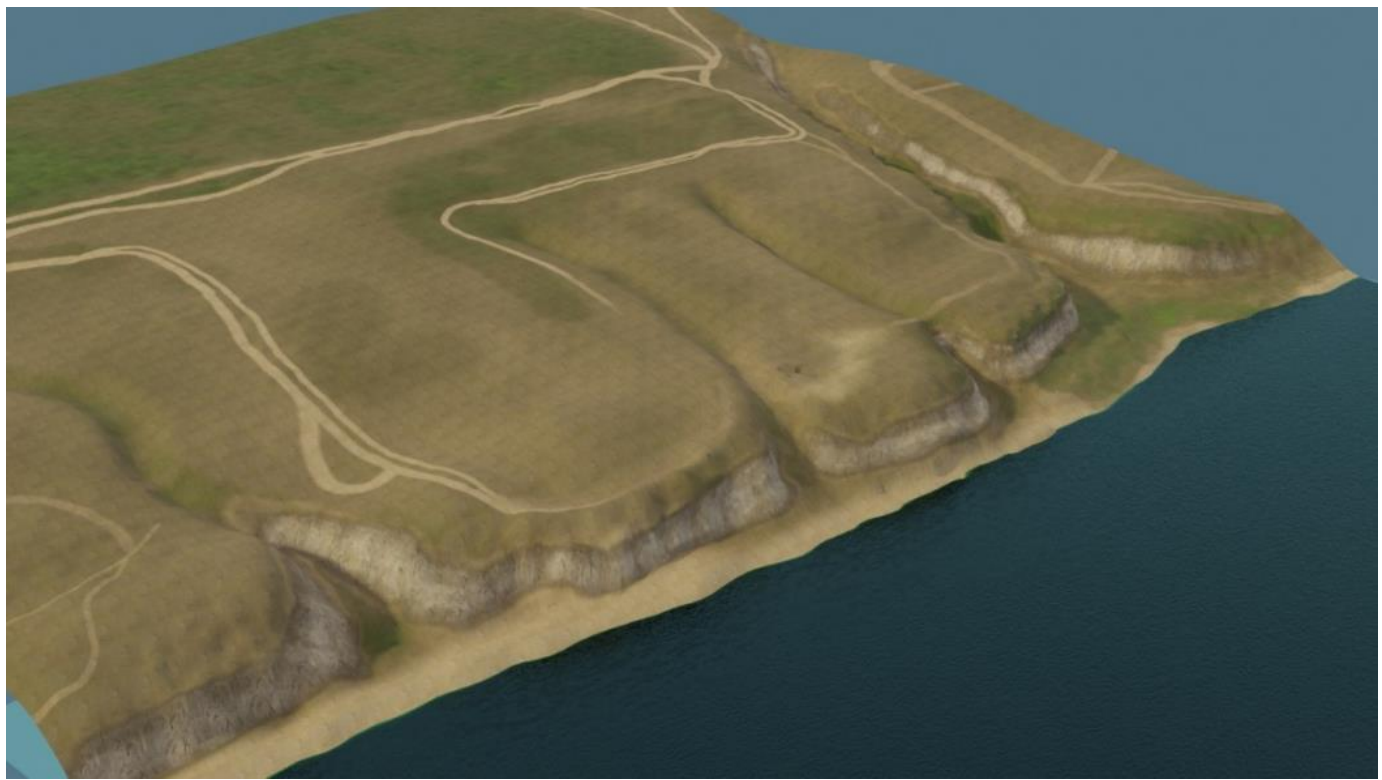

Figure 8. Textures

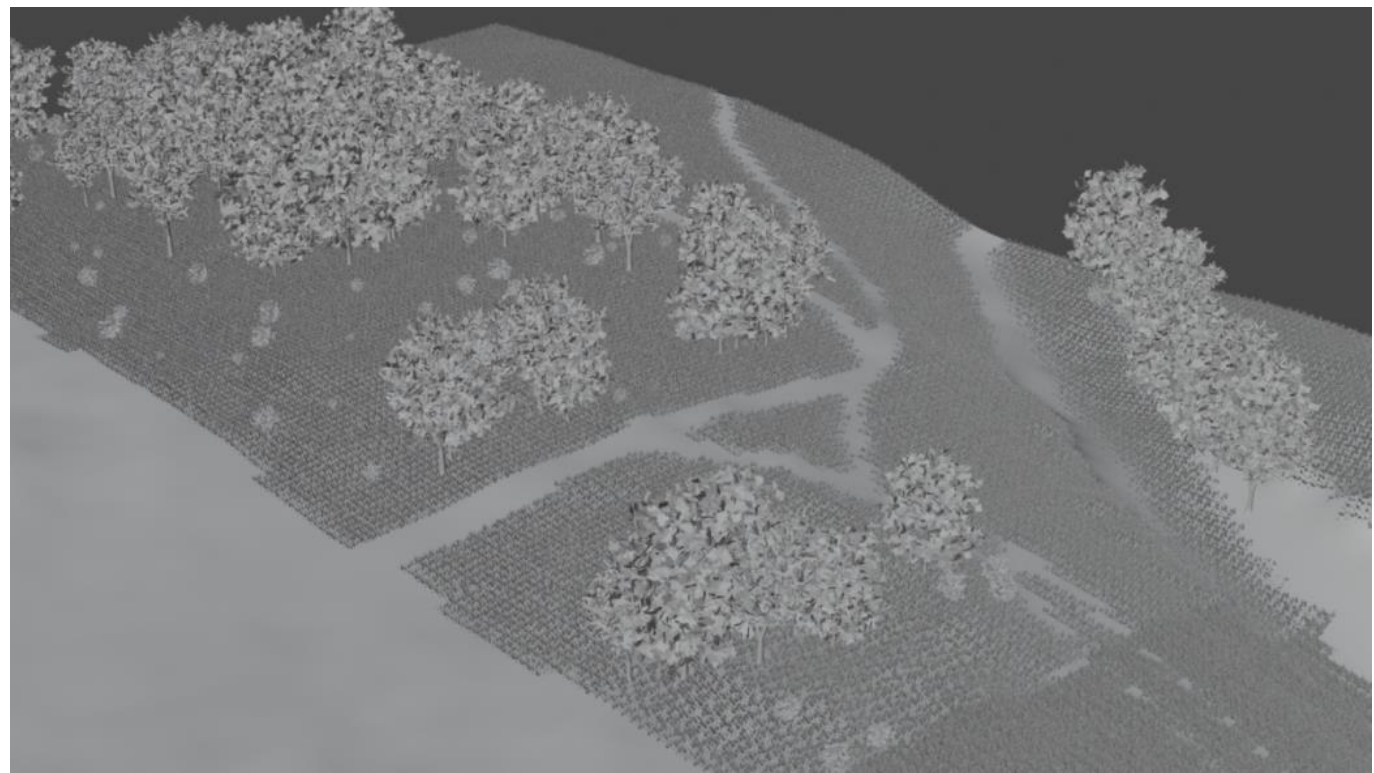

Figure 9. Vegetation in one of the sectors 


\section{Conclusion}

The presented example of working with OSM maps demonstrates the widespread use of three-dimensional modeling technologies in the reconstruction of the required landscape for historical visualization. It's characterized by a variety of approaches and tools, with different technological complexities. In combination with the modeling of architectural objects based on archaeological data, this approach allows to get a visualization of a historical monument and its environment. The reliability of the result is determined by the level of research not only of the object itself, but also, in general, of the cultural and technological specifics of the region in a given period of time. As practice has shown, the most successful are projects created by interdisciplinary teams consisting of historians, archaeologists and specialists related to computer technology. A virtual three-dimensional reconstruction can be not only a spectacular way of visualization, but also should act as a method of humanitarian research. Therefore, there should be opportunities for $3 \mathrm{D}$ modeling by specialists in the humanitarian sphere, and for this it is necessary to create some standards and techniques for virtual threedimensional reconstruction.

\section{Acknowledgements}

The study was carried out with the financial support of the Ministry of Education and Science of the Russian Federation within the framework of the scientific project No. 06332020-0004 "Development of the method of virtual 3D reconstruction of historical objects".

\section{References}

1. Egorov V.L. Historical geography of the Golden Horde of the XIII-XIV centuries. Moscow, Nauka Publ, 1985. 243 p.

2. Ilina O.A. Vodyanskoe Gorodishche - Beldzhamen of Golden Horde - Russian Bezdezh. Modern Problems of Science and Education. Surgery, 2009, vol. 6-3, pp. 39-43.

3. Sukhorukova E.P., Kiyashko A.V., Lapshin A.S., Myskov E.P. History of Vodyansky Settlement Study. Ivzestia of the Volgograd State Pedagogical University, 2010, no. 8 (52), pp. 57-61.

4. Lapshin A.S. Issues of preservation and study of the Vodyansky settlement - the monument of history, archeology and culture of the XIV century in the Lower Volga region. Ivzestia of the Volgograd State Pedagogical University, 2017, no. 9 (122), pp. 168-172.

5. Lapshin A.S., Myskov E.P. Research on the Vodyansky settlement in 2011-2012. Volgograd; Moscow, "Pero" Publ, 2013. 216 p.

6. Myskov E.P., Ilina O.A. Research on the Vodyansky settlement in 2011-2012. Vestnik VolGU. Seriya 4, Istoriya. Regionovedenie. Mezhdunarodnye otnosheniya, 2018, vol. 23, no. 3, pp. 220-221.

7. Rumyantsev M.V., Smolin A.A., Baryshev R.A., Rudov I.N., Pikov N.O. Virtual reconstruction of historical and cultural heritage objects. Journal of Applied Informatics, 2011, no. 6 (36), pp. 62-77.

8. Guidi G., Micoli L., Gonizzi Barsanti S, Malik U. The CHT2 Project: Diachronic 3D Reconstruction of Historic Sites. ISPRS - International Archives of the Photogrammetry, Remote Sensing and Spatial Information Sciences, 2017, no. 08, pp. 309-316. DOI: 10.5194/isprs-archives-XLII-2-W5-309-2017.

9. H. Schumann, W. Müller Visualisierung: Grundlagen und allgemeine methoden / Springer-Verlag, 2013. P.370.

10. Virtual Reconstruction of Historical and Cultural Heritage in the Formats of Scientific Research and Educational Process. Krasnoyarsk, Siberian Federal University, 2012. 196 p.

11. Mixed Reality and Gamification for Cultural Heritage/ Springer International Publishing, 2017, P. XVII+594, DOI: https://doi.org/10.1007/978-3-319-49607-8, , URL https://link.springer.com/book/10.1007/978-3-319-49607-8

12. Ievleva O.T., Karpyuk T.A., Koshevoy A.I. The Visualization of Historical and Theoretical Researches Architectural Heritage. Scientific Visualization, 2014, vol. 6, no. 4, pp. 11-21. 
13. Khapaev V.V., Batsura I.V. 3D computer reconstruction of the ancient and medieval city of Tauric Chersonesos: experience, problems and prospects. Historical Information Science, 2018, no. 4, pp. 39-56. DOI: 10.7256/2585-7797.2018.4.28489. URL: https://nbpublish.com/library read article.php?id=28489

14. Yegorov V.L., Fedorov-Davydov G.A. Study of the mosque on the Vodyansky settlement. Medieval monuments of the Volga region. Moscow, Nauka Publ, 1976, pp. 108-167.

15. Noskova L.M. Mosaics and majolica of medieval cities of the Volga region. Medieval monuments of the Volga region. Moscow, Nauka Publ, 1976, pp. 7-37.

16. Zelevinskaya E.D. Cult architecture of the Golden Horde: Origins and traditions. The Volga River Region Archaeology, 2016, no. 2 (16), pp. 44-67.

17. Zelevinskaya E.D. Cult architecture of the Golden Horde: Origins and traditions. The Volga River Region Archaeology, 2019, no. 2 (28), pp. 78-97.

18. Golden Horde. Volgograd Regional Museum of Local Lore. URL: https://vokm134.ru/arheologija/zolotaja-orda.

19. Mechet khana Uzbeka v Starom Krymu [Khan Uzbek Mosque in the Old Crimea]. Proekt «Otkrytaya arkheologiya». URL: https://открытаяархеология.pф/monuments/мечетьхана-узбека-в-старом-крыму.

20.Small Minaret. The great Bulgarian. Bulgarian State Historical and Architectural MuseumReserve. URL: http://www.bolgar.info/m_minaret.php.

21. Cathedral Mosque and Grand Minaret. The great Bulgarian. Bulgarian State Historical and Architectural Museum-Reserve. URL: http://www.bolgar.info/s_mechet.php.

22. OpenStreetMap.ru URL: https://openstreetmap.ru

23. Nemtinov V.A., Borisenko A.B., Nemtinova Y.V., Gorelov A.A., Tryufilkin S.V. Implementation of technology for creating virtual spatial-temporal models of urban development history. Scientific Visualization, 2018, vol. 10, no. 3, pp. 99-107. DOI: 10.26583/sv.10.3.07. 